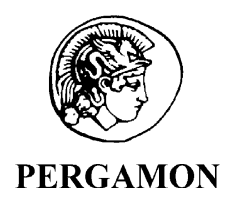

Higher Education Policy 15 (2002) 99-103

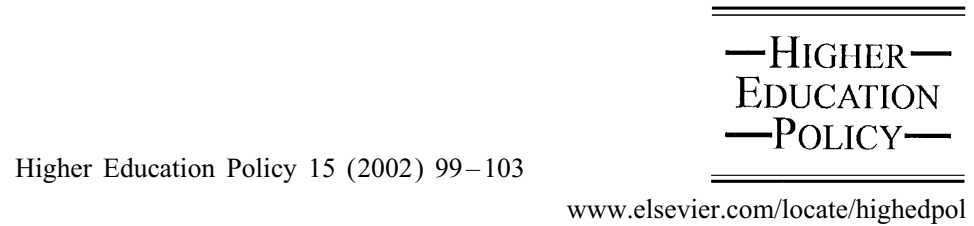

Editorial

\title{
Introduction: higher education for sustainable development
}

Over the past 30 years, the global community has been debating the significance of environmental problems and the meaning and urgency of sustainable development. The major purpose of the World Summit on Sustainable Development (WSSD), taking place in Johannesburg, South Africa, form August 26 to September 4, 2002, is to affirm the importance of sustainable development for the 21 st century, define the central elements of sustainability, and identify priorities for action.

Over the past 10 years, many United Nations summits have been held, focusing on population, women, cities, food, social development, and other topics. Each has added more insights to our understanding of sustainable development. This vision of development requires not only economic progress but peace, economic and social justice, concern for future generations, and for nature itself. This requires significant shifts in the policies of our national governments, the practices of our organizations, corporations, and communities - and in our individual consumer choices.

Colleges and universities are vested by society with the task of discerning truth, imparting values, and socializing students to contribute to social progress and the advancement of knowledge. They have a profound responsibility to impart the moral vision and technical knowledge needed to ensure a high quality of life for future generations. Sustainable development is the current context in which higher education must focus its mission. Many higher education institutions have responded to this major challenge of our time by making sustainability central to the critical dimensions of university life-curriculum, research and scholarship, operations, community outreach and service, student opportunities, institutional mission and structure, and faculty and staff development and rewards.

In 2000, four organizations agreed to form a Global Higher Education for Sustainability Partnership (GHESP), to combine their strengths in an effort to mobilize higher education institutions to support sustainable development. The organizations are:

- The Association of University Leaders for a Sustainable Future (ULSF) serves as the Secretariat of over 280 signatories of the Talloires Declaration in over 40 countries and promotes education for sustainability based on the Earth Charter; ${ }^{1}$

\footnotetext{
${ }^{1}$ See www.ulsf.org.
} 
- COPERNICUS-Campus, formerly a Programme of the Association of European Universities, is responsible for the University Charter for Sustainable Development, signed to date by over 290 university heads in 36 European countries; ${ }^{2}$

- The International Association of Universities (IAU) provides an international centre of cooperation among 800 member universities and institutions of higher education. IAU developed and adopted the Kyoto Declaration; ${ }^{3}$

- The United Nations Educational, Scientific and Cultural Organization (UNESCO) is the task manager for the implementation of Chapter 36, "Education, Public Awareness and Training", of Agenda 21 and for the international work programme on education of the United Nations Commission on Sustainable Development. ${ }^{4}$

GHESP partners believe that higher education must play a central role within the overall process of achieving sustainable development. The partners are convinced that if the leaders of major disciplines and institutions do not make sustainability a central academic and organizational focus, it will be impossible to create a just, equitable, and sustainable future.

Together IAU, ULSF and COPERNICUS represent over 1000 universities that have committed to making sustainability a central focus of their teaching and practice. Roughly one third of these signatory institutions are from the global south, and one-fifth from countries in the former Soviet Union and Warsaw Pact nations.

The Talloires and Kyoto Declarations, the University Charter for Sustainable Development and other international statements like them, have contributed to a global consensus on higher education for sustainable development. The themes, which nearly all international declarations share, include promoting sustainability in all relevant disciplines; research on sustainable development issues; the 'greening' of university operations; engaging in inter-university cooperation; forming partnerships with government, NGOs and industry; and most consistently, the moral obligation of higher education to work for a sustainable future. All of the priorities in Chapter 36 of Agenda 21 are reaffirmed in these declarations.

The GHESP partners realize that the adoption of these declarations does not necessarily translate into the implementation of their basic commitments. We also realize that sustainability means many different things, depending on the cultural, economic, political, and geographic setting of the college or university. Thus in our initial Memorandum of Understanding, and reiterated in the 2001 Lüneburg Declaration, ${ }^{5}$ we committed to the following specific actions:

- Promote expanded endorsement and full implementation of the Talloires, Kyoto, and Copernicus declarations;

\footnotetext{
${ }^{2}$ See www.copernicus-campus.org.

${ }^{3}$ See www.unesco.org/iau/.

${ }^{4}$ See www.unesco.org.

${ }^{5}$ In October 2001, in Lüneburg, Germany at the annual conference of COPERNICUS-Campus, participants and the four GHESP partners adopted the Lüneburg Declaration, calling for a renewed commitment to higher education for sustainable development. For the full text, see www.lueneburg-declaration.de.
} 
- Produce an action-oriented tool kit for universities, managers, administrators, faculty and students designed to move from commitment to concrete action. The tool kit would include: implementation strategies for colleges and universities in teaching, research, operations and outreach; an inventory of available resources; and an inventory of best practices with a compilation of case studies;

- Enhance the development of regional centres of excellence in both developed and developing countries, and effective networking among them.

The GHESP partners also agreed to conduct an assessment of progress towards sustainability in higher education within the context of the 10-year review of progress since the Earth Summit undertaken for the WSSD in August 2002 in Johannesburg, South Africa. This assessment and the critical tasks described above attempt to build on Agenda 21 and various international conferences and programs that followed the Earth Summit, which were relevant to further defining and promoting sustainability in higher education. ${ }^{6}$

Our assessment has indicated considerable confusion concerning the meaning of sustainability. Sustainability as an organizing principle in higher education is a relatively new concept. It gained salience only after the World Commission on Environment and Development in 1987. Steven C. Rockefeller writes:

"The concept of sustainability has a narrower and broader meaning. An activity is sustainable if it can be continued indefinitely. Patterns of production and consumption are considered to be ecologically sustainable if they respect and safeguard the regenerative capacities of our oceans, rivers, forests, farmlands, and grasslands. However, using the term in the broader sense, one can talk about building a sustainable global society. In this connection, sustainability includes all the interrelated activities that promote the long-term flourishing of Earth's human and ecological communities." 7

Professor Rockefeller was Chair of the Drafting Committee of the Earth Charter and is an expert on the international agreements and laws which contributed to its foundation. Begun before Rio and only completed in March 2000, the Earth Charter is a shared vision of ethical principles for sustainable development. Written over a period of 10 years and involving the participation of hundreds of thousands of citizens across cultures, it is the most widely vetted and participatory international agreement in history-truly a "peoples" charter. The Earth Charter is being used as an inspiration and ethical framework for sustainability education, and is discussed in the articles in this joint issue. ${ }^{8}$

\footnotetext{
${ }^{6}$ In particular, the International Work Programme on Education, Public Awareness and Training for Sustainability adopted by the UN Commission on Sustainable Development (1996); the International Conference on Environment and Society (Thessaloniki, 1997); the World Conference on Higher Education (Paris, 1998); the World Conference on Science (Budapest, 1999); and the World Education Forum (Education for All) (Dakar, 2002).

${ }^{7}$ Rockefeller, Steven C., The Earth Charter: Building a Global Culture of Peace, A speech given at the Earth Charter Community Summits, Tampa, FL. September 29, 2001.

${ }^{8}$ For more information on the global Earth Charter Initiative, see www.earthcharter.org.
} 
Our assessment has also indicated little progress in implementing Chapter 36 of Agenda 21. As UNESCO reported to the UN Commission on Sustainable Development in 1996, "education is the forgotten priority of Rio". While many institutions have started sustainability initiatives and formed partnerships to promote the agenda, few national governments have made it a priority and there has been no fundamental change within higher education.

In March 2001, ULSF convened a consultation on "Assessing Progress Toward Sustainability in Higher Education" in Washington, DC, which explored the current status of sustainability in higher education and identified factors that hinder or enhance sustainable development as a central concern. Papers were commissioned for this meeting, four of which are included here. Two others were commissioned for a "Sustainability and Higher Education" conference in Brisbane, Australia in December 2001.

IAU and ULSF undertook this research project to gather significant writing on sustainability in higher education. Scholarly consideration of research paradigms, historical development of the sustainability movement, and practical perspectives on sustainability in higher education in various settings provide, we hope, resources to assist you in moving your college or university down the path toward sustainability.

These papers were written by scholars from a diversity of disciplines and types of tertiary institutions. They are both senior and young researchers and they come from five continents. Their theoretical perspectives and methods of analysis vary. By seeking this array of scholarship we hope to provide an introduction to this inchoate field of higher education for sustainability. By addressing the fundamental issues that arise and speaking to them from a diversity of perspectives, we believe these scholars have made an important contribution to an emerging literature.

Tarah Wright's review of the history of sustainability declarations, various institutional sustainability statements, and discussion of emerging themes therein is a cogent introduction to the definition and current state of environmental sustainability in higher education. Dr. Wright is a young Canadian scholar active in North American research circles on this topic.

The problematique of defining sustainability is a crucial one for higher education. The critical analysis of the contextual meaning of the term encouraged by Arjen Wals and Bob Jickling provides useful perspectives on the issue. Wals, from the Netherlands and Jickling, from Canada, have contributed to the critique of sustainability since the introduction of the term.

Konai Thaman explains that sustainable development and issues related to a sustainable future are culturally derived. One of Oceania's most widely read and recognized poets, Thaman is a powerful voice from the region of the world that is most negatively affected by the developed world's unsustainable practices. She makes her points in "a Pacific way" including the orality of poetry.

John Fien discusses in turn, empirical-analytical, interpretive, critical, and poststructural research paradigms in an exposition of their viability in helping us gain knowledge and understanding of sustainability in higher education. Fien, a leader in education for sustainability in the Asia-Pacific region, provides an eclectic approach to the epistemological and methodological questions raised in this field. 
The efforts to measure sustainability and address parameters for assessing it across institutions are reviewed by Michael Shriberg. He is a doctoral candidate and a leader in a new generation of scholars at work on these topics.

In the first of three case studies, Alejandrina Segreda examines the particular perspectives on sustainability and peace in Costa Rica that gave rise to the commitments of her institution. This case study sheds light on the possibilities for such a social discourse in moving a university to sustainability.

Ludmila A. Verbitskaya, Natalia B. Nosova, and Ludmila L. Rodina focus on attempts to introduce sustainable development education into the curriculum at the St. Petersburg State University. They offer a model for reforming the system of national higher education to make it more relevant to present needs and conditions in Russia and more supportive of sustainable development.

Victoria M. Segovia and Angelina P. Galang discuss efforts in higher education to foster sustainable development in the Philippines, with specific focus on the pioneering work of Miriam College. They argue that for sustainable development to occur it must take root in the consciousness and cultures of society, a task in which education plays a critical part.

Readers of this jointly-published special issue of this journal are a key audience. It is likely that you are affiliated with an institution that has made a commitment to sustainability through one of the several declarations described above. With this issue, we encourage you to more actively participate in the community of scholars of sustainability active around the world, and to become more deeply involved in the research and capacity-building programme that we are developing with our GHESP partners.

\section{Peter Blaze Corcoran Wynn Calder Richard M. Clugston}

Richard M. Clugston is director of the Association of University Leaders for a Sustainable Future and the Earth Charter USA Campaign. He is publisher and editor of Earth Ethics and deputy editor of The International Journal of Sustainability in Higher Education. His recent publications have focused on higher education for sustainable development and the Earth Charter. Dr. Clugston can be reached at e-mail: rmclugston@aol.com.

Peter Blaze Corcoran is Professor of Environmental Studies and Environmental Education at Florida Gulf Coast University; he teaches courses in sustainability, environmental philosophy, and environmental literature. $\mathrm{He}$ is also Senior Fellow in Education for Sustainability at University Leaders for a Sustainable Future. He is active in the Earth Charter Initiative and serves as a member of the Earth Charter Education Advisory Committee. His research includes international environmental education, higher education for sustainability, and significant life experiences leading to environmental sensitivity. Dr. Corcoran can be reached at e-mail: pcorcora@fgcu.edu.

Wynn Calder is the associate director of the Association of University Leaders for a Sustainable Future. He is editor of the ULSF report, The Declaration news editor for the International Journal of Sustainability in Higher Education, and has published recently on higher education for sustainable development in the US. Mr. Calder is co-ordinatior of the North American Higher Education Network for Sustainablity and the Environment (HENSE). He can be reached at e-mail: wynncalder@aol.com. 